\title{
Avaliação de folhas de bambu na produção de cerveja
}

\section{Fernando D. Sanches*, Aline D. C. de Brito, Flávio L. Schmidt}

\section{Resumo}

O bambu, em virtude de seu grande potencial agronômico e social, constitui uma cultura em ascensão no Brasil. As folhas de bambu, utilizadas na cultura oriental como fonte de compostos antioxidantes, apresentam grande potencial para aplicação na indústria de alimentos. Assim, o objetivo do projeto foi estudar as propriedades das folhas de bambu, visando a sua aplicação em cerveja. Caracterizaram-se as folhas de quatro espécies de bambu quanto à sua composição centesimal e aos compostos fenólicos e estudou-se o efeito do tempo de secagem e de adição no processo sobre os compostos fenólicos. Notou-se que as folhas de B. tuldoides, após secagem a $60^{\circ} \mathrm{C}$, aliadas a um tempo de adição de 10 ou 30 minutos do final da etapa de fervura resultou nos maiores teores de compostos fenólicos.

\section{Palavras-chave:}

Fermentação, antimicrobiano, estabilidade.

\section{Introdução}

O bambu vem ganhando destaque com recentes pesquisas de aplicação da farinha de colmo jovem em produtos de panificação. É uma cultura de alta taxa de crescimento, excelente sequestrador de carbono e de alto potencial agronômico ${ }^{1}$. Industrialmente pode ser explorado o broto para fabricação de conservas ou extração de fibras; os colmos maduros para a construção civil, móveis e utensílios; e as folhas, amplamente aplicadas na medicina chinesa, apresentam alta capacidade antioxidante e antimicrobiana. Algumas cervejarias estrangeiras já adicionam o extrato de folhas de bambu a seus produtos, trazendo um apelo de saudabilidade, no entanto, os efeitos desta adição no processo e nas propriedades tecnológicas da bebida ainda não foram estudados. Dessa forma, o objetivo do trabalho foi caracterizar as folhas das espécies Dendrocalamus asper, Bambusa tuldoides, Phyllostachys nigra e Phyllostachys edulis e estudar os efeitos do processamento sobre seus compostos fenólicos, visando a sua aplicação em cerveja.

\section{Resultados e Discussão}

A composição centesimal das folhas das espécies de bambu estudadas é apresentada na Tabela 1 .

Tabela 1. Dados (em base seca) da composição centesimal das folhas frescas.

\begin{tabular}{|c|c|c|c|c|}
\hline Amostra & Proteínas & Lipídeos & Cinzas & Carbs.* $^{*}$ \\
\hline D. asper & $15,16 \pm 0,33$ & $5,12 \pm 0,34$ & $12,78 \pm 0,32$ & 41,85 \\
\hline B.tuldoides & $12,23 \pm 0,49$ & $3,54 \pm 0,15$ & $15,82 \pm 0,34$ & 29,48 \\
\hline P. nigra & $13,47 \pm 0,14$ & $3,40 \pm 0,12$ & $14,90 \pm 0,66$ & 35,78 \\
\hline P. edulis & $14,68 \pm 0,32$ & $3,78 \pm 0,70$ & $9,15 \pm 1,24$ & 38,28 \\
\hline
\end{tabular}

${ }^{*}$ Carbs. = carboidratos totais por diferença

Todas as espécies apresentam alto teor de carboidratos, (açúcares, amido e fibras), além de baixo teor lipídico e proteico. A análise de sólidos solúveis indicou que $B$. tuldoides contém uma maior quantidade de açúcares.

O estudo do tempo de adição das folhas no processo de fabricação da cerveja indicou que a sua incorporação a 10 ou a 30 minutos do final da etapa de fervura resulta em maiores quantidades de compostos fenólicos.

$\mathrm{O}$ estudo dos efeitos da secagem (Tabela 2) mostrou que a secagem a $60^{\circ} \mathrm{C}$ resultou em valores médios de compostos fenólicos significativamente maiores. Além disso, seu uso é vantajoso do ponto de vista energético, uma vez que o tempo de secagem é consideravelmente menor, o que permite maior controle da operação (Figura 1).

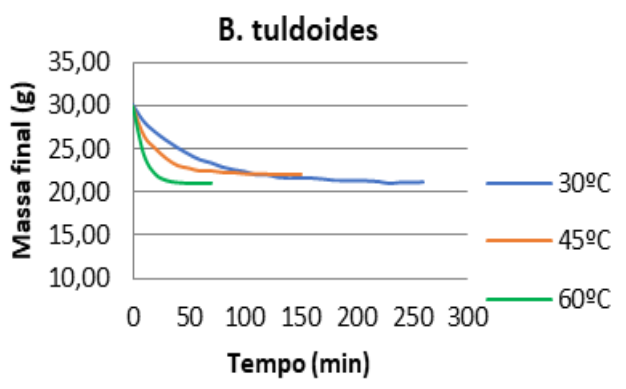

Figura 1. Curva de secagem da espécie Bambusa tuldoides a $30^{\circ} \mathrm{C}, 45^{\circ} \mathrm{C}$ e $60^{\circ} \mathrm{C}$

Tabela 2. Efeito da secagem a diferentes temperaturas sobre a estabilidade de compostos fenólicos, expressos em concentração média de ácido gálico (mg ácido gálico/100 g folha).

\begin{tabular}{|c|c|c|c|c|}
\hline Tratamento & D. asper & B. tuldoides & P. nigra & P. edulis \\
\hline Sem tratamento & $4,0 \pm 0,2^{\mathrm{cB}}$ & $7,8 \pm 0,2^{\mathrm{cA}}$ & $3,8 \pm 0,1^{\mathrm{cB}}$ & $3,0 \pm 0,0^{\mathrm{dC}}$ \\
\hline $\mathbf{3 0}^{\circ} \mathbf{C}$ & $6,6 \pm 0,1^{\mathrm{b}}$ & $8,8 \pm 0,1^{\mathrm{b}}$ & $7,2 \pm 0,3^{\mathrm{a}}$ & $6,5 \pm 0,2^{\mathrm{b}}$ \\
\hline $\mathbf{4 5}^{\circ} \mathbf{C}$ & $6,8 \pm 0,2^{\mathrm{b}}$ & $9,5 \pm 0,2^{\mathrm{a}}$ & $6,7 \pm 0,1^{\mathrm{b}}$ & $5,4 \pm 0,1^{\mathrm{c}}$ \\
\hline $\mathbf{6 0}^{\circ} \mathbf{C}$ & $7,2 \pm 0,3^{\mathrm{a}}$ & $9,7 \pm 0,2^{\mathrm{a}}$ & $6,9 \pm 0,2^{\mathrm{ab}}$ & $7,2 \pm 0,2^{\mathrm{a}}$ \\
\hline
\end{tabular}

Médias com letras minúsculas diferentes na mesma coluna diferem significativamente pelo teste de Tuckey $(p<0,05)$. Médias com letras maiúsculas diferentes na mesma linha diferem significativamente pelo teste de Tuckey $(p<0,05)$

Observa-se que, a $60^{\circ} \mathrm{C}$, a espécie que apresenta maior teor de fenólicos é $B$. tuldoides.

\section{Conclusões}

Os resultados sugerem que a secagem a $60^{\circ} \mathrm{C}$ é vantajosa por diminuir o tempo da operação e resultar em maior teor de fenólicos totais. A espécie escolhida para aplicação na cerveja foi $B$. tuldoides por seu maior teor de fenólicos a $60^{\circ} \mathrm{C}$ e os testes finais (influência sobre as características gerais da cerveja, fermentação, formação e estabilidade da espuma, trub e vida de prateleira) estão em andamento.

\section{Agradecimentos}

Ao $\mathrm{CNPq} / \mathrm{PIBIC}$ e à Pró-Reitoria de Pesquisa (PRP) UNICAMP pela bolsa de iniciação científica.

${ }^{1}$ Felisberto, M. H. F.; Miyake, P. S. E.; Beraldo, A. L. e Clerici, M. T. P. S.

Food Research International 2017, 101, 96-102. 